\title{
Biogas Development in China to Achieve Carbon Neutrality
}

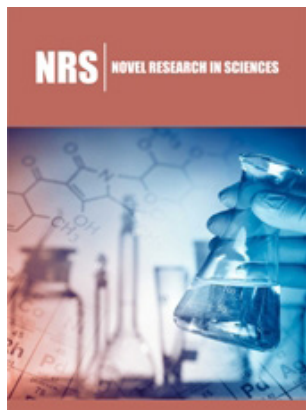

*Corresponding author: He Y, School of Atmospheric Sciences, Sun Yat-sen University, China

Submission: 师 July 01, 2021

Published: 僵July 09, 2021

Volume 8 - Issue 3

How to cite this article: He Y.. Biogas Development in China to Achieve Carbon Neutrality. Nov Res Sci. 8(3). NRS. 000689. 2021.

DOI: 10.31031/NRS.2021.08.000689

Copyright@ He Y., This article is distributed under the terms of the Creative Commons Attribution 4.0 International License, which permits unrestricted use and redistribution provided that the original author and source are credited.
He Y*

School of Atmospheric Sciences, Sun Yat-sen University, China

\begin{abstract}
To meet China's goal of reaching carbon-neutrality by 2060, the state will have to surmount tremendous technical and bureaucratic obstacles in transitioning its coal-dependent economy toward renewable energy. Biomass has a carbon neutral life cycle and great potential for promoting climate change benefits. The main problems restricting biogas development in China are the lack of integrity and unified policy, and the contradiction between longer duration of environmental PPP (Public-Private-Partnership) project and social capital always pursuing short-term profits. PPP is an institutional arrangement of policy interaction, which means that there is a legally structured partnership between government and private actors. Therefore, we propose that China should further accelerate the construction of basic and standardized PPP legal system, further promote the innovation development of PPP model, and establish effective risk-sharing and credit constraint mechanisms. According to the degree of government involvement and the role of the market, biogas development can be divided into three main stages: the government support phase, the transitional phase and the market-driven phase. A policy path that adapts to China's electricity market and biogas development is designed based on the three development stages, and it strictly follows the principles of development, coordination and innovation.
\end{abstract}

Keywords: Carbon-neutrality; Renewable energy; Biogas; PPP model; Market-driven

\section{Introduction}

On September 22, 2020, at the General Debate of the $75^{\text {th }}$ Session of the UN General Assembly, Chinese President Xi Jinping announced that China will strive to achieve a peak in carbon emissions by 2030 and carbon neutrality by 2060, which aims to realize the goal of the Paris Agreement. China's pledge to carbon neutrality not only has a profound impact on its economic reforms, but also spurs the country to be more proactive in global climate governance [1]. The achievement of carbon peak depends primarily on policies (e.g. energy system optimization, energy market reform, emission reduction through market mechanisms), while the achievement of carbon neutrality is mainly driven by technologies (e.g. zero-carbon waste treatment, carbon-neutral process, carbon-neutral materials, biogas production, ecological carbon sink, artificial photosynthesis, etc.). Developing renewable energy and gradually reducing the share of coal are the focus of China's carbon emission reduction [2]. Biogas is a carbon neutral fuel to be generated from garbage, livestock manure, sewage sludge, etc $[3,4]$. Biogas as a renewable and clean energy has a great potential for development. Although China's rapid development of biogas has promoted power source structure optimization, the associated power regulatory laws and supporting measures are imperfect. To some extent, the existing regulation policies and mechanisms are inadequate for promoting the development of biogas [5]. Therefore, it is necessary to study the biogas regulation issue under the condition of large-scale renewable energy grid connection to achieve China's carbon neutrality. 
Biogas Industry Development Status and Related Policies and Regulations in China

China has turned its attention to the clean energy industry to reduce energy consumption and reduce greenhouse gas emissions. The wind energy, bioenergy, solar energy as the representative of the new energy to obtain rapid development [6]. The low carbon, clean trend of world's energy consumption emerging. Methane industrialization is the strategic need of clean energy development in China. Industrialization of methane has the very good social benefits, be helpful for the adjustment of husbandry structure and to promote employment. In the early 1970s, the Chinese government popularized in rural biogas projects, biogas generated from the pool used for cooking and gradually developed to lighting and heating [7]. By the end of 2013, China's rural households using biogas reached 40.83 million units. Rural household biogas total production reached 13.673 billion $\mathrm{m}^{3}$. Per unit production is $374 \mathrm{~m}^{3}$. Ministry of agriculture in conjunction with the national development and Reform Commission continue to support largescale biogas project pilot projects and large-scale biogas projects on 2016. Further exploration and innovation support policies and institutional mechanisms, so that the scale of rural biogas project development, ecological cycle, comprehensive utilization, intelligent management, efficiency and promote the direction of transformation and upgrading. To implement the Party Central Committee and the State Council on the work of rural biogas deployment decisions, further improve the " $13^{\text {th }}$ Five-Year" period of rural biogas upgrading work, the government promulgated the “National Rural Biogas Development 13 ${ }^{\text {th }}$ Five-Year Plan" on 2017.

The present policy of biogas digesters in china focus on the investment on the construction so that the massive project cannot be profitable or even be abandoned, which resulting in the lower investment efficiency and waste of resources. By implementing the biogas product subsidy policy to change exiting subsidy model is indispensable measure to promote the continuous operation of biogas projects. Especially in the early stages of the biogas projects, through the end product price adjustment and subsidy policy, the project operator owners profit. Such as raising the basic price of the Internet is an effective practice. High power efficiency, more subsidies, low power efficiency, low subsidies. Changes in government subsidies can be better allocation of funds, thereby enhancing the social benefits of biogas. However, from the longterm view, it is better to optimize the operation mode, that is to say, introducing the PPP project.

\section{PPP Model in Biogas}

Chinese government should introduce the PPP (Public-PrivatePartnership) model to establish a diversified investment mechanism, improve the preferential policies for rural biogas, create a fair competitive environment for products, accelerate the improvement of the standard system of biogas, and strengthen international cooperation and exchanges. PPP model is a new project financing model, it refers to the partnership between the government and private organizations, based on the concession agreement formed a "benefit sharing, risk sharing, full cooperation" partnership [8]. The purpose is to provide a certain public goods and services in the PPP mode, the government to participate in the whole process of operation, but put a part of government's responsibility transfer to the social body (enterprise) take the form of a franchise. To authorize the private sector to replace the government for the construction, operation and management of public infrastructure and provide the public services to the public. In this way, not only the government can reduce the financial burden, but also social subjects (enterprises) will reduce investment risk, so as to achieve win-win cooperation.

The PPP model for biogas projects has four advantages $[9,10]$ :

1. Solving the capital shortage problem. The institutional problem arising from government sponsorship, along with the limited capital source, are commonly recognized as the key roots behind this phenomenon. Potential solutions include introducing market mechanism as well as luring private funds. By doing so, capital shortage is believed could be alleviated to a large extent.

2. Increasing productivity. Advanced technology from private sector is primary source of this efficiency gain. For instance, two parities (government and private enterprises) could cooperate during the setup stage by mutually benefiting each other via various spillovers like technological and managerial knowhow. 3. Incentivizing private investment. This is fundamentally due to its huge potential profit. Meanwhile, private enterprises, by participating government-sponsored projects, can access various privileges including tax exemption, discounted land as well as utility priority.

3. Being less risk compared solely government-led projects. Principally, the fund is sourced from multiple parities. This directly reduced the default risk. On management side, both government official and private firm managers have to participate the process evaluation and quality control simultaneously. And this feature has further reduced bureaucratic risk and moral hazard.

\section{Proposal for a Biogas Regulation Policy Development Path}

According to PPP model, government and private sectors should have a greater cooperation. In order to better promote the development of biogas and regulate the behaviors of the market, rational biogas regulation policies should consider market operation, environmental strategies. And biogas regulation policy reform should be implemented in stages. The proposed regulatory policy to promote biogas consumption in China is shown as Figure 1. 


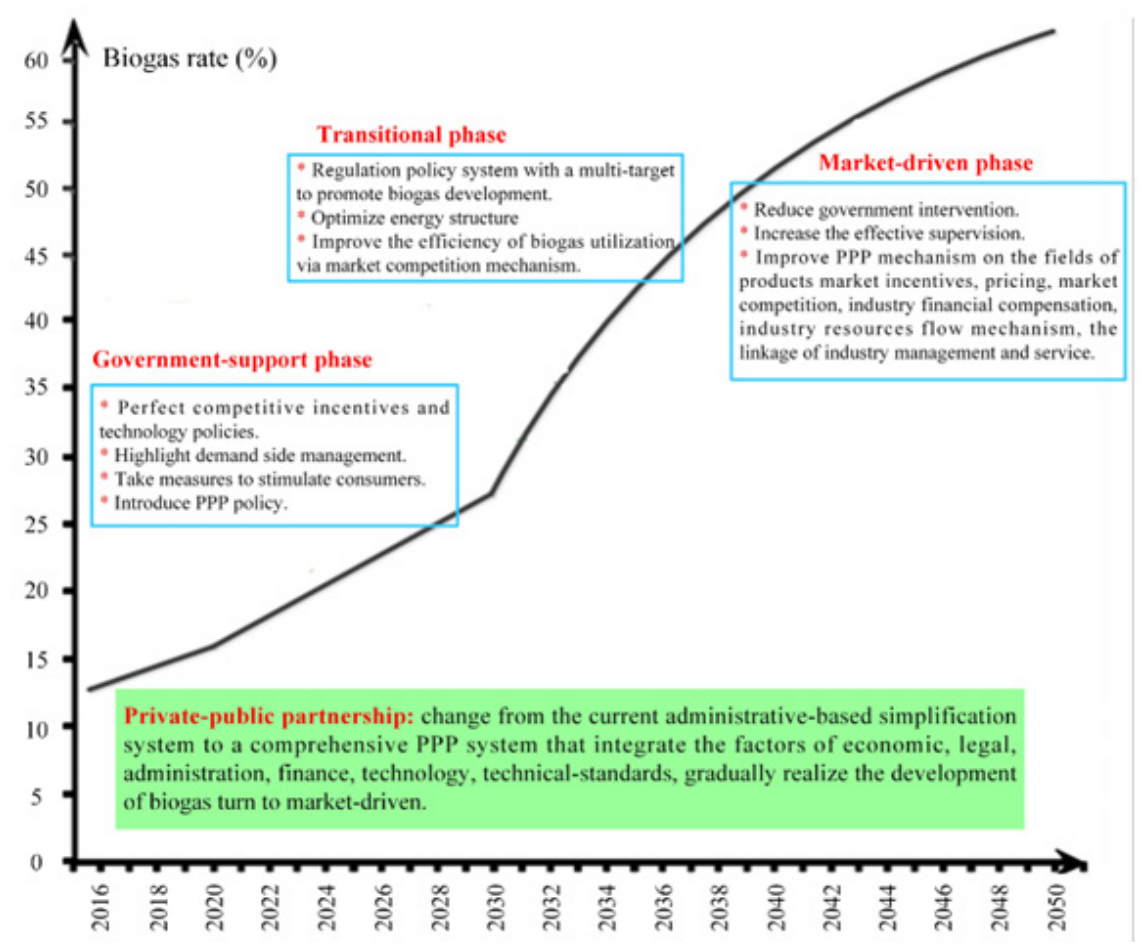

Figure 1: The biogas regulation policy development path in China.

1. The government support phase: biogas development is in the government support and policy guiding phase. In the government-supported phase, China's industrialization and urbanization will enter a period of accelerated development, during which resource and environmental constraints will continually grow. Energy saving and emission reduction, as well as a rapid response to climate change, will become the main point of the national economic policies. At the same time, renewable energy development is given a higher priority as a strategic choice with the trend of the electricity market reform and internationalization. China will intensify the regulation in the economic, social and antitrust fields.

2. The transition phase: biogas development is in the infancy combination stage of promoting and market driven policies. In the transitional phase, the electricity market in China will be gradually established. To some extent, the developing pricing mechanism reform and market mechanism will gradually promote renewable energy development, diverting towards the combination of policy support and marketdriven development. During this period, biogas regulation will implement appropriate elastic power regulatory policies, relaxing electricity market access, investment and generation bidding. In order to solve the problems of external diseconomies and information asymmetries that exist in the electric power industry, the Government will focus on the control of power supply obligations, electricity general obligations, environmental protection and technological progress.

3. The market-driven phase: biogas development is in the stage of constantly reducing administrative intervention and gradually increasing effective regulation. In the market-driven phase, the biogas regulation policy will focus on two points: namely, to reduce government intervention and increase the effective supervision. The Government will pay attention to the construction of market-adjusting mechanisms, and then the market will play an important role in adjusting the relationship between the biogas electricity demand and the sales prices. In addition, to stimulate biogas market scale and industrialization, the government will gradually improve the biogas development mechanism in the fields of product market incentives, pricing, market competition, industry financial compensation, the industry resources flow mechanism and the linkage of industry management and service.

\section{Acknowledgement}

This work was supported by the China Postdoctoral Science Foundation (Grant No. 2020M672944) and the Fundamental Research Funds for the Central Universities, Sun Yat-sen University (Grant No. 2021qntd29).

\section{References}

1. Dong L, Miao G, Wen W (2021) China's carbon neutrality policy: Objectives, impacts and paths. East Asian Policy 13(1): 5-18.

2. Liu X, Zhao T, Chang CT (2021) China's renewable energy strategy and industrial adjustment policy. Renewable Energy 170: 1382-1395.

3. Li F, Cheng S, Yu H, Yang D (2016) Waste from livestock and poultry breeding and its potential assessment of biogas energy in rural China. Journal of Cleaner Production 126: 451-460.

4. Yamamoto T, Uchiyama S, Matsune H, Kishida M (2020) Improvement of gasification efficiency with consideration for microwave input power 
on biogas reformulation by microwave plasma assisted combustion. IOP Conference Series: Materials Science and Engineering 778: 012098.

5. He Y, Yang X, Pang Y, Tian H, Rui W (2016) A regulatory policy to promote renewable energy consumption in China: Review and future evolutionary path. Renewable Energy 89: 695-705.

6. Yan J, Boehm RF, Yang H (2015) Handbook of Clean Energy Systems. Wiley Publisher, USA.

7. Yu L, Kuang Y, Huang N, Wu Z, Xu L (2008) Popularizing householdscale biogas digesters for rural sustainable energy development and greenhouse gas mitigation. Renewable Energy 33(9): 2027-2035.
8. Heldeweg MA, Sanders M, Harmsen M (2015) Public-private or privateprivate energy partnerships? Toward good energy governance in regional and local green gas projects. Energy Sustainability \& Society 5: 1-12.

9. Keating B, Keating M (2013) Private firms, public entities, and microeconomic incentives: Public Private Partnerships (PPPs) in Australia and the USA. International Journal of Organizational Analysis 21: 176-197.

10. Moszoro MW, Gasiorowski P (2008) Optimal capital structure of publicprivate partnerships. Social Science Electronic Publishing 08: 1-10. 